Elsevier Editorial System(tm) for Veterinary Parasitology

Manuscript Draft

Manuscript Number:

Title: Detection of bovine Babesiosis in Mozambique by a novel hot-start PCR method

Article Type: Research Paper

Section/Category:

Keywords: Babesia bigemina; Babesia bovis; hot-start PCR; Molecular diagnosis; aspartic protease

Corresponding Author: PhD Student Tiago M Martins,

Corresponding Author's Institution: INETI

First Author: Tiago M Martins

Order of Authors: Tiago M Martins; Olívia C Pedro; Rubina A Caldeira; Virgílio E do Rosário; Luís Neves; Ana Domingos

Manuscript Region of Origin:

Abstract: 


\section{Detection of bovine Babesiosis in Mozambique by a novel hot-start PCR method}

3 Tiago M. Martins ${ }^{\mathrm{a}, \mathrm{b}^{*}}$, Olívia C. Pedro ${ }^{\mathrm{c}}$, Rubina Caldeira ${ }^{\mathrm{a}}$, Virgílio E. do Rosário ${ }^{\mathrm{b}}$, Luís

4 Neves $^{\mathrm{d}}$, and Ana Domingos ${ }^{\mathrm{a}, \mathrm{b}}$

$6 \quad{ }^{a}$ UTPAM, INETI, Est. Paço do Lumiar 1649-038 Lisboa, Portugal

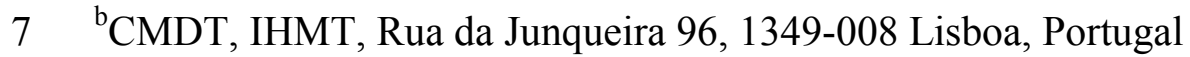

$8{ }^{\mathrm{c}}$ Faculdade de Veterinária, Univ. Eduardo Mondlane, Av. de Moçambique km 1.5,

9 Maputo, Mozambique

$10{ }^{\mathrm{d}}$ Centro de Biologia Molecular da Univ. Eduardo Mondlane, Av. de Moçambique km 1.5,

11 Maputo, Moçambique

13 Babesiosis is a tick borne disease (TBD) caused by parasites of the genus Babesia, with 14 considerable worldwide economic, medical, and veterinary impact. Babesiosis and other 15 TBDs were considered responsible for $50 \%$ of the deaths of cattle occurred in

16 Mozambique in the first year after importation from neighbouring countries.

17 Here, we present the detection of B. bigemina and B. bovis in cattle from Mozambique 18 and the development of a novel PCR method. For this study, blood samples were

19 collected in one farm located near Maputo city. The samples were analyzed using a

20 previously described nested PCR and a novel hot-start PCR method. Primers were

21 selected for the hot-start PCR based on the putative gene of an undescribed aspartic

22 protease named babesipsin, present in both B. bovis and B. bigemina. The combination of

23 hot start polymerase and long primers (29-31bp) were in this study determinant for the 
24 successful amplification and detection in only one PCR. The babesipsin hot-start PCR is

25 a fast, simple, and sensitive method, with some advantages over current methods. A total

26 of 117 field samples were tested by hot-start PCR, and 90 were positive for B. bigemina

27 (77\%), 82 were positive for B. bovis (70\%), 61 were mixed infections (52\%) and only 6

28 were negative (5.1\%). The results confirm that this area of Mozambique is endemic for

29 Babesiosis, and that this TBD should be regarded as a threat for imported cattle.

30

31 Keywords: Babesia bigemina; Babesia bovis; hot-start PCR; Molecular diagnosis;

32 aspartic protease

33

34 *Corresponding author. Tel. +351 210924712; fax: +351 217162626; E-mail address:

35 tiago.martins@ineti.pt (Tiago Martins) 


\section{Introduction}

38 In recent years, efforts have been made to rebuild the livestock population in

39 Mozambique. Cattle have been imported mostly from the neighbouring countries

40 Zimbabwe and South Africa. The success of this approach is being impaired by high

41 mortality among the imported cattle, which is estimated at around $50 \%$ within the first

42 year (Alfredo et al., 2005). Tick Borne Diseases (TBDs), particularly babesiosis,

43 anaplasmosis and cowdriosis are arguably the major causes of mortality. Although the

44 distribution and prevalence of TBDs in Mozambique is mostly unknown, seroprevalence

45 of Babesia bovis (39\%) and Anaplasma marginale (63\%) was recently reported for Tete

46 province (Alfredo et al., 2005).

47 Bovine babesiosis in Africa, and particularly in Mozambique, is caused by B. bovis and

48 Babesia bigemina (Uilenberg, 2006). There are reports of Babesia occultans in South

49 Africa (Gray and De Vos, 1981) and possibly Nigeria (Dipeolu and Amoo, 1984), but the

50 prevalence and distribution of this benign form of cattle babesiosis is unknown. On the

51 other hand, the tick vector responsible for the transmission of B. occultans, Hyalomma

52 marginatum rufipes, was identified in Mozambique, suggesting that B. occultans may

53 therefore be present. In vitro cultivation of B. occultans was accomplished (Niekerk and

54 Zweygarth, 1996), but unfortunately there are no published sequences of B. occultans in

55 the public databanks, and there is also no Polymerase chain reaction (PCR) detection

56 method available. Nevertheless, molecular studies have to bear in mind the presence of

57 this and possibly other unidentified species. Detection methods based on the 18S rRNA

58 gene sequence or other genus conserved sequences, can originate false positives as these 
59 sequences are expected to be more conserved with the sequences from unsequenced and 60 unidentified Babesia spp..

61 B. bovis was detected in Mozambique by serologic tests (Alfredo et al., 2005), but these

62 methods are less sensitive and specific in the detection of the carrier state of animals and

63 do not usually distinguish between past exposure and present infections. PCR based

64 techniques constitute an alternative method for the direct detection of Babesia in carrier

65 cattle. The carrier state occurs after acute or primary infections, in which the animals are

66 not clinically ill. Identification of carrier animals is important for the assessment of

67 infection risk, given that they serve as reservoirs for infection of ticks and, ultimately,

68 wider infection of the herd (Calder et al., 1996).

69 Several PCR based methods have been published that allow the detection of B. bovis and

70 B. bigemina. More specifically, two methods have been used by various authors for the

71 detection of Babesia from blood and ticks: the multiplex nested PCR (nPCR) for the

72 detection of B. bovis and B. bigemina (Figueroa et al., 1993; Almeria et al., 2001; Gayo et

73 al., 2003; Oliveira et al., 2005; Costa-Júnior et al., 2006) and the reverse line blot

74 hybridization assay (RLB) (Gubbles et al., 1999; Georges et al., 2001; Brígido et al.,

75 2004; Oura et al., 2004). Both methods appear to have similar sensitivities at $10^{-6} \%$

76 parasitemia (Gubbles et al., 1999; Costa-Júnior et al., 2006). However, it is interesting

77 that the non-multiplex nested PCR has an increased detection of $10^{-7} \%$ parasitemia

78 (Oliveira-Sequeira et al., 2005). Here, we present the development of a faster and

79 sensitive method in the detection of B. bovis and B. bigemina in field samples, and in face

80 of the results the state of bovine babesiosis in Mozambique will be briefly addressed. 


\section{Materials and methods}

82

85 A total of 117 blood samples were collected from cattle in the province of Maputo,

86 Mozambique. The samples were collected in September near Umbeluzi in the Boane

87 District, mainly from Friesian Cattle. Approximately $2-4 \mathrm{ml}$ of blood was collected from

88 the coccygeal vein into ethylenediaminetetraacetic acid (EDTA) buffered vacutainer

89 tubes. Samples were kept at $4{ }^{\circ} \mathrm{C}$ while being transported to the laboratory at the Faculty

90 of Veterinary of Maputo. The blood was stored at $-20^{\circ} \mathrm{C}$ until DNA extraction.

91

92

\subsection{DNA extraction}

94 DNA extraction was performed according to Centeno-Lima et al. (2003). Two hundred

95 microlitres of EDTA buffered whole blood was added to $500 \mu$ l phosphate-buffered

96 saline (PBS), vortexed for $10 \mathrm{~s}$ and then centrifuged at $16000 \mathrm{~g}$ for $5 \mathrm{~min}$. The cells pellet

97 was washed with PBS three more times or until the supernatant was clear. The pellet was

98 then ressuspended with $100 \mu \mathrm{l}$ of lysis buffer [50 $\mathrm{mM} \mathrm{KCl}, 0.5 \%(\mathrm{v} / \mathrm{v})$ Tween-20, $10 \mathrm{mM}$

99 Tris- $\mathrm{HCl}(\mathrm{pH} 8.0)$ and $10 \mu \mathrm{g}$ of proteinase $\mathrm{K}$ added before use], incubated overnight in a

100 water bath at $56^{\circ} \mathrm{C}$ and heated for $10 \mathrm{~min}$ at $100{ }^{\circ} \mathrm{C}$ to inactivate proteinase $\mathrm{K}$. Samples

101 were stored at $-20{ }^{\circ} \mathrm{C}$.

102 


\subsubsection{Primers}

107 The primers used in hot-start PCR amplification (Table 1), are localized within the

108 putative aspartic proteinase babesipsin genes from both B. bovis and B. bigemina. The

109 babesipsin putative gene sequences were identified in the Sanger Institute databases: in

110 the B. bovis EST Sequencing Project (de Vries et al., 2006) and in the B. bigemina 111 genome project.

112 The oligonucleotide primers were designed using the online GeneFisher program 113 (Giegerich et al., 1996) with the following parameters: $\mathrm{G}+\mathrm{C}$ content from 40 to $60 \%$, 114 melting temperature between 60 and $80^{\circ} \mathrm{C}$, and primer size between 27 and 31 bp (Table 115 1). The expected size using babesipsin primers is $614 \mathrm{bp}$ for B. bigemina and 426 bp for 116 B. bovis. The amplification products span 2 partial exons and 1 intron.

117 The primer sequences described by Figueroa et al. (1993) were used in nPCR; BoF/R and $118 \mathrm{BilA} / \mathrm{B}$ the outer primers, BoFN/RN and BilAN/BN the inner or nested primers (Table 1).

\subsubsection{Babesipsin hot-start PCR}

122 The babesipsin hot-start PCR reaction mixtures $(20 \mu \mathrm{l})$ contained $16 \mathrm{mM}\left(\mathrm{NH}_{4}\right)_{2} \mathrm{SO}_{4}, 67$ $123 \mathrm{mM}$ Tris-HCl (pH8.8), 0.01\% (v/v) Tween-20, $2.5 \mathrm{mM} \mathrm{MgCl}_{2}, 0.5$ pmol each primer, $124200 \mu \mathrm{M}$ each dNTP, $1 \mathrm{U}$ of Superhot Taq DNA polymerase (Bioron GmbH), and $1 \mu \mathrm{l}$ 125 total DNA. Hot-start PCR was carried out in a PTC-200 MJ Research thermocycler for 40 
126 cycles. Each cycle consisted of $20 \mathrm{~s}$ of denaturation at $95{ }^{\circ} \mathrm{C}$ ( $1 \mathrm{~min}$ for the first cycle), 30

127 s of annealing at $69^{\circ} \mathrm{C}$, and $45 \mathrm{~s}$ of extension at $72^{\circ} \mathrm{C}$.

128 Twenty random PCR products were gel purified and sequenced in outsourcing at STAB

129 Vida, Portugal.

130

$131 \quad$ 2.3.3. $n P C R$

132

133 The first PCR using the primers described by Figueroa et al. (1993), was carried out using 134 the same buffer as described for babesipsin hot-start PCR, 1 U DFS-Taq DNA 135 polymerase (Bioron $\mathrm{GmbH}$ ), 0.5 pmol outer primers, $1 \mu \mathrm{l}$ total DNA and the 136 thermocycler program described by Oliveira et al. (2005): 35 cycles $\left(1 \mathrm{~min}\right.$ at $95{ }^{\circ} \mathrm{C}, 1$ $137 \min$ at $60^{\circ} \mathrm{C}$ for $B$. bovis and $64{ }^{\circ} \mathrm{C}$ for B. bigemina, 1 min $30 \mathrm{~s}$ at $72{ }^{\circ} \mathrm{C}$ ) and a final 138 extension step at $72{ }^{\circ} \mathrm{C}$ for $5 \mathrm{~min}$. The same conditions of the first PCR were used in $139 \mathrm{nPCR}$ apart from using inner primers, $2 \mu \mathrm{l}$ of the first PCR products as template and an 140 annealing temperature of $65^{\circ} \mathrm{C}$ for B. bovis and $70{ }^{\circ} \mathrm{C}$ for B. bigemina.

144 Ten microlitres of PCR products were separated by electrophoresis in $1.2 \%$ agarose gel 145 containing ethidium bromide in $0.5 \mathrm{x}$ TBE buffer $(44.5 \mathrm{mM}$ Tris- $\mathrm{HCl}, 44.5 \mathrm{mM}$ Boric 146 Acid and $1 \mathrm{mM}$ EDTA, $\mathrm{pH}$ 8.3). After electrophoresis, PCR products were visualized by 147 transillumination with UV light. 
153 Of the 117 samples, 30 were analyzed by nPCR for comparison with the hot-start PCR

154 method. The nPCR reactions using the primers described by Figueroa et al. (1993),

155 resulted in amplification from field samples of the desired products, but showed some

156 unspecific background amplification when using B. bigemina primers. The unspecific

157 amplification is in the same range as the desired product, making difficult the

158 interpretation of results, mainly for positive samples. In the first PCR no bands were

159 visible (not even using hot start polymerase), possibly due to low levels of parasitemia. In

160 the second or nPCR, 25 samples were positive for B. bigemina (83\%) and 26 were

161 positive for B. bovis $(87 \%)$.

165 The combinations using the babesipsin primers described in this study and genomic DNA 166 (kindly provided by Dr. Varda Shkap from Kimron Veterinary Institute, Israel), allowed

167 the amplification of single band products with the expected size (results not shown).

168 Hot-start PCR using field samples also allowed the amplification of single band products

169 with the expected size (see Figure 1 and 2). Sequences of twenty random PCR products, 170 for both Babesia spp., confirmed the specificity of amplification. There was no 
171 amplification of PCR products when a regular Taq polymerase was used instead of the 172 hot-start polymerase.

173 From the total 117 samples, 90 were positive for B. bigemina $(77 \%)$ and 82 were positive

174 for B. bovis (70\%). 61 were reported as mixed infections (52\%) and only 6 were negative 175 (5.1\%). In comparison with the 30 samples analyzed by the nPCR method, 23 were 176 positive for B. bigemina (77\%) and also 23 were positive for B. bovis $(77 \%)$, but not

177 always were the same samples positive for both, and only one sample was negative for

178 both. Some samples were only positive using the hot-start PCR method, and some were 179 only positive using the nPCR. 


\section{Discussion}

182 In this study carried out at $30 \mathrm{~km}$ from Maputo, in Mozambique, almost the entire herd 183 was positive (95\%) for $B$. bigemina and/or $B$. bovis. The high detection of both $B$. 184 bigemina (77\%) and B. bovis $(70 \%)$ infections in cattle from Mozambique is similar to 185 another endemic region of the world. Oliveira et al. (2005) also observed that, in São 186 Carlos, SP, Brazil, there was infection in high levels in cattle with B. bigemina (88\%) and 187 B. bovis $(92 \%)$ using the nPCR as detection method. Nevertheless, other studies should 188 be conducted in other areas in Mozambique to confirm the endemic status of Babesiosis 189 in this country. Efforts to rebuild the stock population should consider the Babesiosis 190 threat especially when importing cattle from countries that adopt stricter control 191 measures.

192 Although there are several reported methods in the literature describing the detection of

193 B. bigemina and B. bovis, only some have been tested with field samples, and only a few

194 have been used globally: the nPCR (Figueroa et al., 1993; Almeria et al., 2001; Gayo et 195 al., 2003; Oliveira et al., 2005; Costa-Júnior et al., 2006) and the RLB (Gubbles et al., 196 1999; Brígido et al., 2004; Oura et al., 2004). One of the goals of this work was to 197 develop a method that could offer some advantages over the current ones, using cost 198 effective methodologies, and equipments available in local molecular biology 199 laboratories.

200 In this study the nPCR was a little more sensitive than the hot-start PCR (Table 2). This 201 could be the result of the hot-start PCR being more sensitive to contaminants in the DNA 202 samples, since in the second or nested PCR there is a ten fold dilution of the possible 
203 PCR inhibitors. In any case, some samples were only positive using the hot-start PCR

204 method, and some were only positive using the nPCR. This can be expected when the

205 samples have low parasitemias, because the frequency of detection decreases with the

206 decrease in parasitemia (Calder et al., 1996).

207 The nPCR requires two consecutive PCR, and therefore more preparation and running

208 time than the new hot-start PCR. The RLB assay also requires more preparation and

209 special equipment, but can be used in the detection of several species from different

210 genera, and consequently can be a better method to have a broader view of TBDs

211 infections.

212 The development of the hot-start PCR served the initial purposes. The method is

213 sensitive, simple and fast, and no special equipment is needed. The hot-start PCR method

214 allows the screening of a high number of samples in a short period of time and is

215 therefore suited for epidemiological studies.

216 In the first PCR of the nPCR method, using BoF and BoR or BilA and BilB primers,

217 there was no amplification, even when using hot start polymerase. When using the

218 babesipsin longer primers with higher melting temperatures (Table 1) and a non hot-start

219 polymerase, there was also no amplification. This appears to infer that only the

220 combination of a hot-start polymerase and long primers (29-31 bp) allows the

221 amplification from field samples that contain pathogen DNA in low concentrations. The

222 use of hot-start polymerases and 30 bp primers with melting temperatures around $64{ }^{\circ} \mathrm{C}$

223 can eventually be used in the development of new detection methods for pathogens that

224 are present in low levels as in the case of the carrier state of B. bovis and B. bigemina. 
228 Tiago Martins would like to acknowledge Fundação para a Ciência e a Tecnologia (FCT),

229 Portugal, for his PhD grant. We would like to recognize Dr. Varda Shkap from Kimron

230 Veterinary Institute, Israel, for the kind donation of high quality genomic DNA from $B$.

231 bovis and B. bigemina.

\section{References}

235 Alfredo, A., Jonsson, N., Finch, T., Neves, L., Molloy, J., Jorgensen, W., 2005.

236 Serological Survey of Babesia bovis and Anaplasma marginale in cattle in Tete Province, 237 Mozambique. Trop. Anim. Health Pro. 37, 121-131.

239 Almeria, S., Castellà, J., Ferrer, D., Ortuño, A., Estrada-Peña, A., Gutiérrez, J.F., 2001.

240 Bovine piroplasms in Minorca (Balearic Islands, Spain): a comparison of PCR-based and

241 light microscopy detection. Vet. Parasitol. 99, 249-259.

243 Brigido, C., da Fonseca, I.P., Parreira, R., Fazendeiro, I., do Rosario, V.E., Centeno-

244 Lima, S., 2004. Molecular and phylogenetic characterization of Theileria spp. parasites in 245 autochthonous bovines (Mirandesa breed) in Portugal. Vet. Parasitol. 123, 17-23.

247 Calder, J.A., Reddy, G.R., Chieves, L., Courtney, C.H., Littell, R., Livengood, J.R., 248 Norval, R.A., Smith, C., Dame, J.B., 1996. Monitoring Babesia bovis infections in cattle 
249 by using PCR-based tests. J. Clin. Microbiol. 34, 2748-2755.

250

251 Centeno-Lima, S., do Rosario, V., Parreira, R., Maia, A.J., Freudenthal, A.M., Nijhof,

252 A.M., Jongejan, F., 2003. A fatal case of human babesiosis in Portugal: molecular and 253 phylogenetic analysis. Trop. Med. Int. Health 8, 760-764.

255 Costa-Junior, L.M., Rabelo, E.M.L., Martins Filho, O.A., Ribeiro, M.F.B., 2006.

256 Comparison of different direct diagnostic methods to identify Babesia bovis and Babesia

257 bigemina in animals vaccinated with live attenuated parasites. Vet. Parasitol. 139, 231258236.

260 Dipeolu, O.O., Amoo, A., 1984. The presence of kinetes of a Babesia species in the 261 haemolymph smears of engorged hyalomma ticks in Nigeria. Vet. Parasitol. 17, 41-46.

263 Figueroa, J.V., Chieves, L.P., Johnson, G.S., Buening, G.M., 1993. Multiplex polymerase 264 chain reaction based assay for the detection of Babesia bigemina, Babesia bovis and 265 Anaplasma marginale DNA in bovine blood. Vet. Parasitol. 50, 69-81.

267 Gayo, V., Romito, M., Nel, L.H., Solari, M.A., Viljoen, G.J., 2003. PCR-based detection 268 of the transovarial transmission of Uruguayan Babesia bovis and Babesia bigemina 269 vaccine strains. Onderstepoort J. Vet. Res. 70, 197-204. 
271 Georges, K., Loria, G.R., Riili, S., Greco, A., Caracappa, S. Jongejan, F., Sparagano, O.,

272 2001. Detection of haemoparasites in cattle by reverse line blot hybridisation with a note

273 on the distribution of ticks in Sicily. Vet. Parasitol. 99, 273-286.

274

275 Giegerich, R., Meyer, F., Schleiermacher, C., 1996. GeneFisher - software support for the

276 detection of postulated genes. Proc. Int. Conf. Intell. Syst. Mol. Biol. 4, 68-77.

277

278 Gray, J.S., Vos, A.J.D., 1981. Studies on a bovine Babesia transmitted by Hyalomma

279 marginatum rufipes Koch, 1844. Onderstepoort J. Vet. Res. 48, 215-223.

280

281 Gubbels, J.M., de Vos, A.P., van der Weide, M., Viseras, J., Schouls, L.M., de Vries, E.

282 Jongejan, F., 1999. Simultaneous detection of bovine Theileria and Babesia species by

283 reverse line blot hybridization. J. Clin. Microbiol. 37, 1782-1789.

284

285 Van Niekerk, C.J., Zweygarth, E., 1996. In vitro cultivation of Babesia occultans.

286 Onderstepoort J. Vet. Res. 63, 259-61.

287

288 Oliveira, M., Oliveira-Sequeira, T., Araujo, Jr., J., Amarante, A., Oliveira, H., 2005.

289 Babesia spp. infection in Boophilus microplus engorged females and eggs in Sao Paulo

290 State, Brazil. Vet. Parasitol. 130, 61-67.

291

292 Oliveira-Sequeira, T., Oliveira, M., Araujo, Jr., J., Amarante, A., 2005. PCR-based

293 detection of Babesia bovis and Babesia bigemina in their natural host Boophilus 
294 microplus and cattle. Int. J. Parasitol. 35, 105-111.

295

296 Oura, C.A.L., Bishop, R.P., Wampande, E.M., Lubega, G.W., Tait, A., 2004. Application 297 of a reverse line blot assay to the study of haemoparasites in cattle in Uganda. Int. J. 298 Parasitol. 34, 603-613.

299

300 Uilenberg, G., 2006. Babesia-A historical overview. Vet. Parasitol. 138, 3-10.

301

302 de Vries, E., Corton, C., Harris, B., Cornelissen, A.W., Berriman, M., 2006. Expressed 303 sequence tag (EST) analysis of the erythrocytic stages of Babesia bovis. Vet. Parasitol. $304138,61-74$.

305

306 Wallace, R.B., Shaffer, J., Murphy, R., Bonner, J., Hirose, T., Itakura, K., 1979. 307 Hybridization of synthetic oligodeoxyribonucleotides to PhiX 174 DNA: the effect of 308 single base pair mismatch. Nucl. Acids Res. 6, 3543-3558. 
312 Table 1

313 Primers sequence and melting temperature (Tm)(Wallace et al., 1979).

\begin{tabular}{|c|c|c|c|}
\hline Method/Parasite & Name & Primer sequence & $\operatorname{Tm}\left({ }^{\circ} \mathrm{C}\right)$ \\
\hline \multirow{2}{*}{$\begin{array}{l}\text { hot-start PCR } \\
\text { B. bovis }\end{array}$} & BovBA1F & 5'-CCCGCTCTGGATACCGTAACCATAGGAGA-3' & 64 \\
\hline & BovBA1R & 5'-ATACTGAGGATCCACTCCGCCTAGCATCA-3' & 63 \\
\hline \multirow{2}{*}{$\begin{array}{l}\text { hot-start PCR } \\
\text { B. bigemina }\end{array}$} & BigBA1F & 5'-GGGAGATAAAAATCGGCACGCCCCCGCAA-3' & 66 \\
\hline & BigBA1R & 5'-GAGGATCTATGCCTCCTAACATTATCCGTGA-3' & 62 \\
\hline \multirow{4}{*}{$\begin{array}{l}\mathrm{nPCR} \\
\text { B. bovis }\end{array}$} & $\mathrm{BoF}$ & 5'-CACGAGGAAGGAACTACCGATGTTGA-3' & 60 \\
\hline & BoR & 5'-CCAAGGAGCTTCAACGTACGAGGTCA-3' & 61 \\
\hline & BoFN & 5'-TCAACAAGGTACTCTATATGGCTACC-3' & 56 \\
\hline & BoRN & 5'-CTACCGAGCAGAACCTTCTTCACCAT-3' & 60 \\
\hline \multirow{4}{*}{$\begin{array}{l}\mathrm{nPCR} \\
\text { B. bigemina }\end{array}$} & BiIA & 5'-CATCTAATTTCTCTCCATACCCCTCC-3' & 58 \\
\hline & BilB & 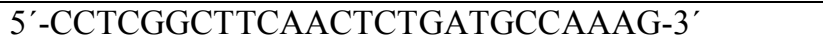 & 61 \\
\hline & BiIAN & 5'-CGCAAGCCCAGCACGCCCCGGTGC-3' & 69 \\
\hline & BiIBN & 5'-CCGACCTGGATAGGCTGTGTGATG-3' & 61 \\
\hline
\end{tabular}

314 
315 Table 2

316 Comparison of methods in the detection of cattle infected with B. bigemina and/or $B$.

317 bovis in Boane district, Mozambique.

\begin{tabular}{|l|c|c|c|}
\hline Method / \# samples & $\mathrm{nPCR} / 30$ & hotPCR / 30 & hotPCR / 117 \\
\hline B. bigemina & $25(83 \%)$ & $23(77 \%)$ & $90(77 \%)$ \\
\hline B. bovis & $26(87 \%)$ & $23(77 \%)$ & $82(70 \%)$ \\
\hline Mixed infections & $21(70 \%)$ & $17(56 \%)$ & $61(52 \%)$ \\
\hline No detection & $0(0 \%)$ & $1(3.3 \%)$ & $6(5.1 \%)$ \\
\hline
\end{tabular}

318 


\section{$319 \quad$ Figures}

320

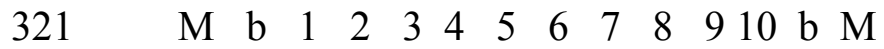

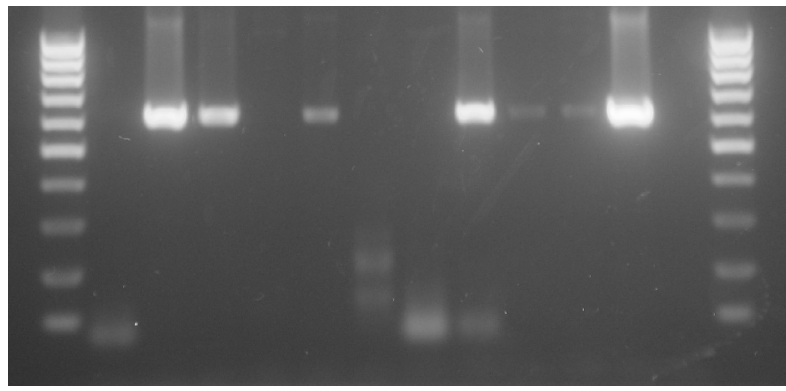

$500 \mathrm{bp}$

323 Figure 1. Hot-start PCR of B. bigemina DNA from field blood samples. DNA was

324 subjected to hot-start PCR for the babesipsin 614 bp sequence amplification using the 325 primers BigBA1F and BigBA1R. M: 100bp DNA ladder marker; b: negative control.

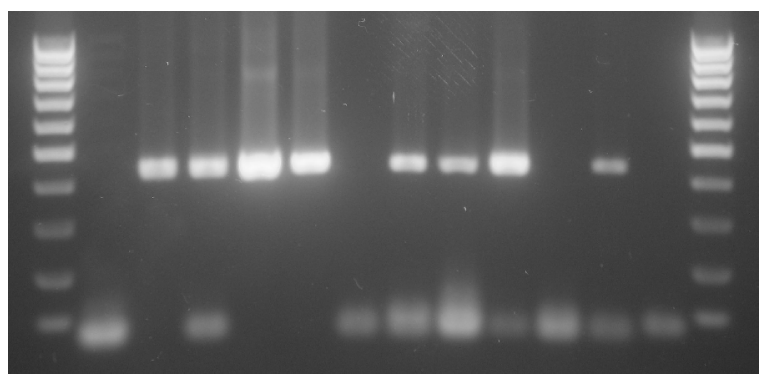

$500 \mathrm{bp}$

329 Figure 2. Hot-start PCR of B. bovis DNA from field blood samples. DNA was subjected

330 to hot-start PCR for the babesipsin 426 bp sequence amplification using the primers

331 BovBA1F and BovBA1R. M: 100bp DNA ladder marker; b: negative control. 
Table 1

Primers sequence and melting temperature (Tm)(Wallace et al., 1979).

\begin{tabular}{|c|c|c|c|}
\hline Method/Parasite & Name & Primer sequence & $\operatorname{Tm}\left({ }^{\circ} \mathrm{C}\right)$ \\
\hline \multirow{2}{*}{$\begin{array}{l}\text { hot-start PCR } \\
\text { B. bovis }\end{array}$} & BovBA1F & 5'-CCCGCTCTGGATACCGTAACCATAGGAGA-3' & 64 \\
\hline & BovBA1R & 5'-ATACTGAGGATCCACTCCGCCTAGCATCA-3' $^{\prime}$ & 63 \\
\hline \multirow{2}{*}{$\begin{array}{l}\text { hot-start PCR } \\
\text { B. bigemina }\end{array}$} & BigBA1F & 5'-GGGAGATAAAAATCGGCACGCCCCCGCAA-3' & 66 \\
\hline & BigBA1R & 5'-GAGGATCTATGCCTCCTAACATTATCCGTGA-3' & 62 \\
\hline \multirow{4}{*}{$\begin{array}{l}\text { nPCR } \\
\text { B. bovis }\end{array}$} & $\mathrm{BoF}$ & 5'-CACGAGGAAGGAACTACCGATGTTGA-3' & 60 \\
\hline & BoR & 5'-CCAAGGAGCTTCAACGTACGAGGTCA-3' & 61 \\
\hline & BoFN & 5'-TCAACAAGGTACTCTATATGGCTACC-3' & 56 \\
\hline & BoRN & 5'-CTACCGAGCAGAACCTTCTTCACCAT-3' & 60 \\
\hline \multirow{4}{*}{$\begin{array}{l}\mathrm{nPCR} \\
\text { B. bigemina }\end{array}$} & BiIA & 5'-CATCTAATTTCTCTCCATACCCCTCC-3' & 58 \\
\hline & BiIB & 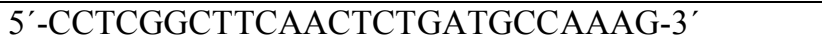 & 61 \\
\hline & BiIAN & 5'-CGCAAGCCCAGCACGCCCCGGTGC-3' & 69 \\
\hline & BiIBN & 5'-CCGACCTGGATAGGCTGTGTGATG-3' & 61 \\
\hline
\end{tabular}


Table 2

Comparison of methods in the detection of cattle infected with $B$. bigemina and/or $B$. bovis in Boane district, Mozambique.

\begin{tabular}{|l|c|c|c|}
\hline Method / \# samples & $\mathrm{nPCR} / 30$ & hotPCR / 30 & hotPCR / 117 \\
\hline B. bigemina & $25(83 \%)$ & $23(77 \%)$ & $90(77 \%)$ \\
\hline B. bovis & $26(87 \%)$ & $23(77 \%)$ & $82(70 \%)$ \\
\hline Mixed infections & $21(70 \%)$ & $17(56 \%)$ & $61(52 \%)$ \\
\hline No detection & $0(0 \%)$ & $1(3.3 \%)$ & $6(5.1 \%)$ \\
\hline
\end{tabular}


Figure 1 here to download high resolution image

$\begin{array}{llllllllllllll}M & b & 1 & 2 & 3 & 4 & 5 & 6 & 7 & 8 & 9 & 10 & b & M\end{array}$

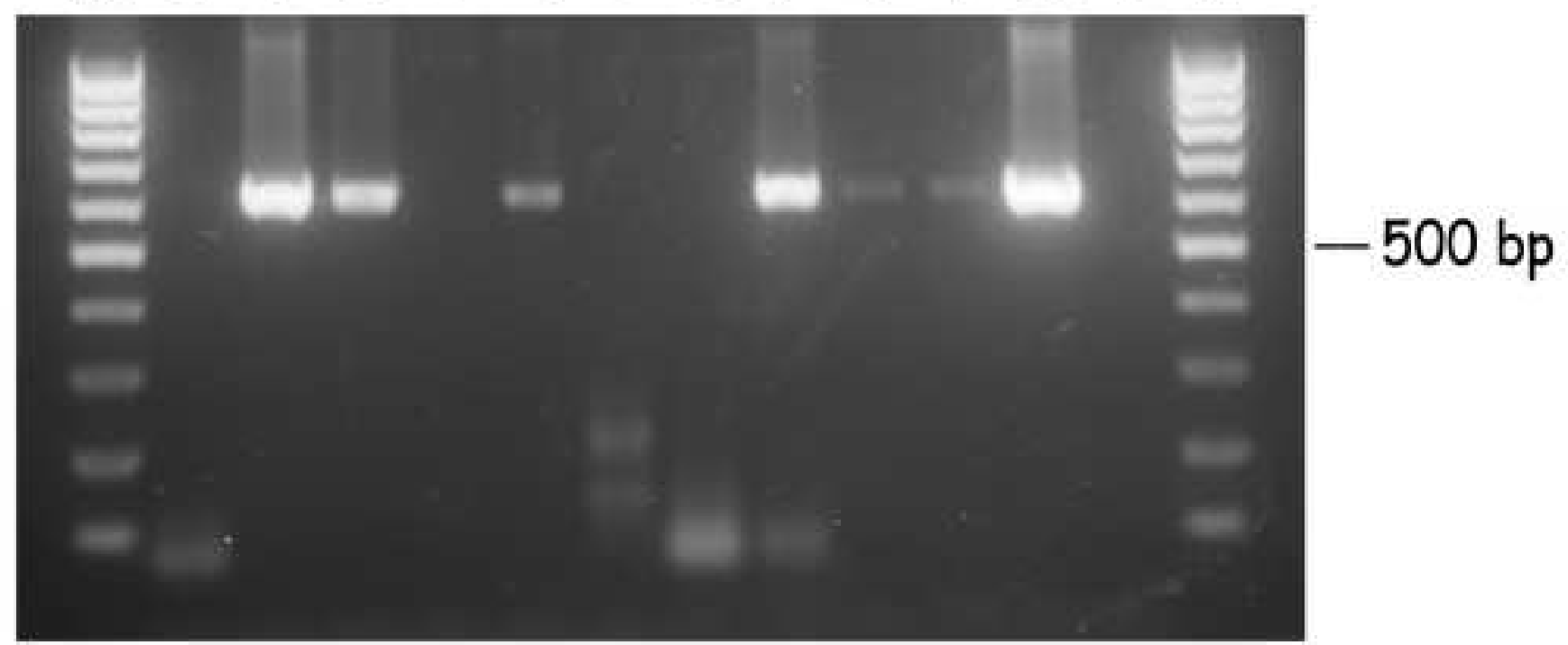


Figure 2
Click here to download high resolution image

\section{$\begin{array}{llllllllllllll}M & b & 1 & 2 & 3 & 4 & 5 & 6 & 7 & 8 & 9 & 10 & b & M\end{array}$}

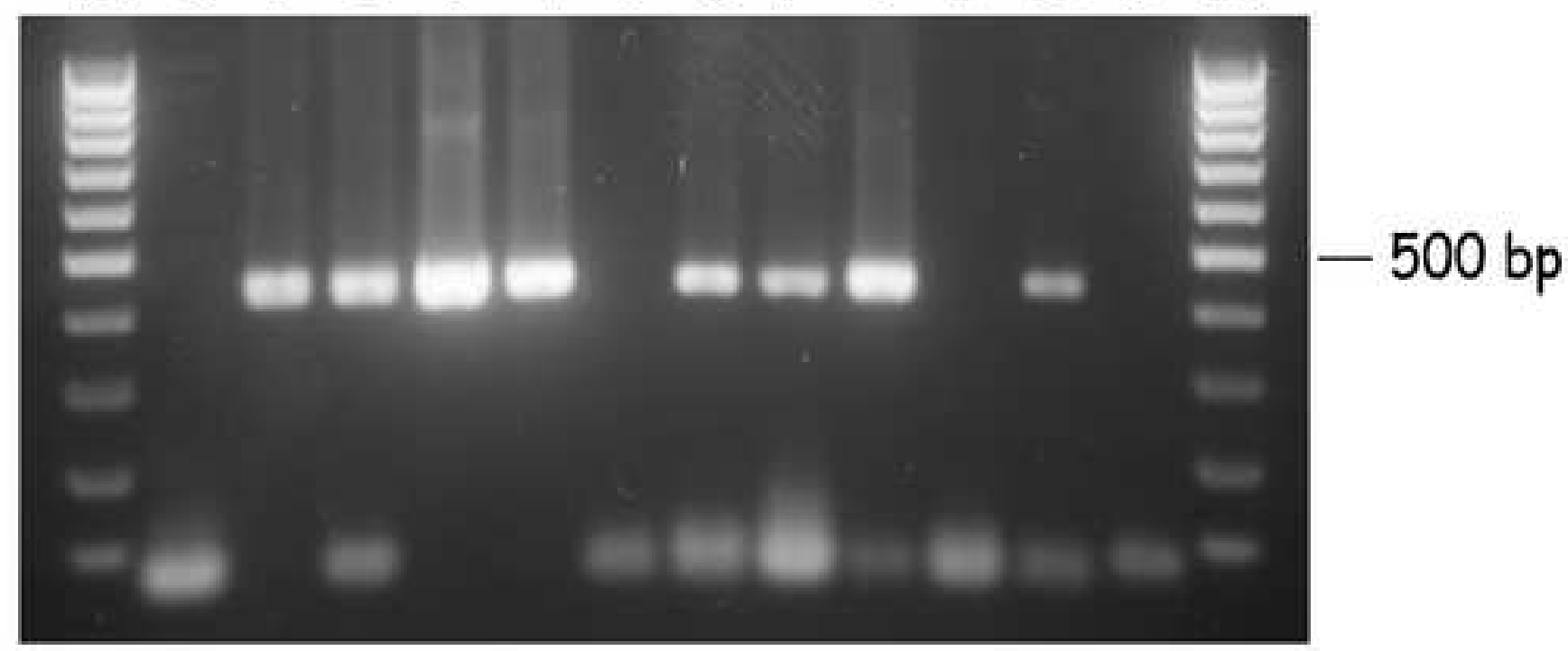

